\title{
Factors Associated with Anxiety-Related Disorders in Children and Adolescents during COVID-19 in Oman: A Cross-Sectional Study
}

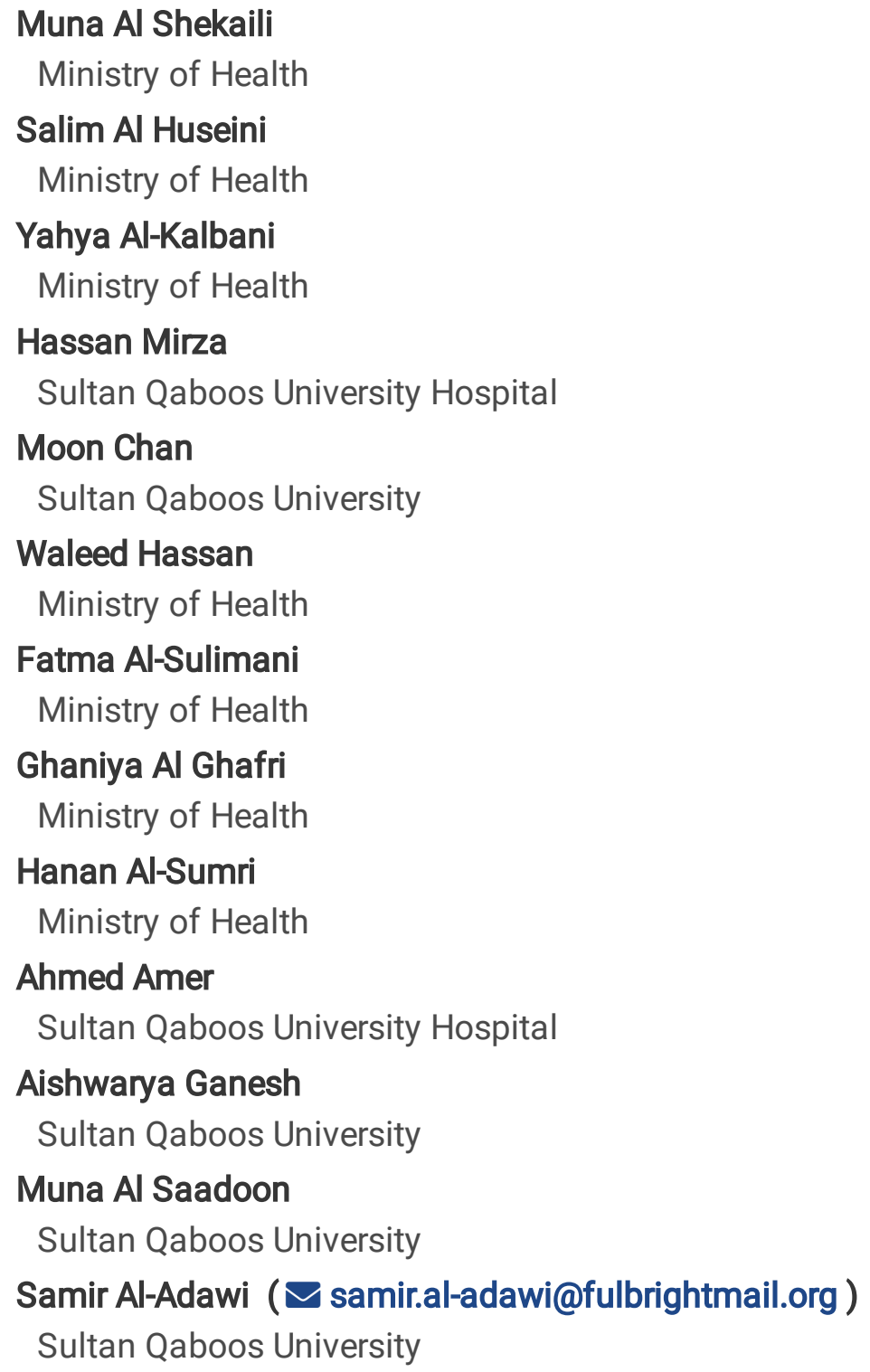

\section{Research Article}

Keywords: psychological distress, COVID-19, anxiety, anxiety-related disorders, child and adolescent, Oman, SCARED.

Posted Date: February 22nd, 2022

DOI: https://doi.org/10.21203/rs.3.rs-982303/v2 
License: (a) (1) This work is licensed under a Creative Commons Attribution 4.0 International License. Read Full License 


\section{Abstract}

BACKGROUND: Reports from different parts of the world suggest that the COVID-19 pandemic and the resultant lockdown and social distancing measures have heralded unprecedented mental health challenges among children and adolescents. To date, there is a dearth of studies emerging from the Arabian Gulf, where the majority of its population are children and adolescents. The study aims to examine the prevalence of anxiety-related disorders and their covariates among children and adolescents in an Arabian Gulf country, Oman.

METHODS: This is a cross-sectional analytic study carried out over two weeks (1st to 15th of August 2020) during the COVID-19 pandemic across Oman. Parents were asked to complete the online survey, which consisted of the parent version of the Screen for Child Anxiety Related Disorders (SCARED-41) scale and questions regarding basic socio-demographic information. Logistic regression was used to identify the contributing variables associated with anxiety-related disorders.

RESULTS: A total of 790 children, 33.3\% ( $n=263)$ fulfilled the criteria for anxiety-related disorders. Logistic regression analysis suggested that anxiety-related disorders in children were significantly associated with three demographic variables. The model shows that children with divorced or separated parents were 1.9 times more likely to have anxiety-related disorders than children of married couples $(O R=1.93, p=0.035)$. Children living in families with an income below USD 1,000/month, were 1.8 times more likely to have anxiety-related disorders than a family with an income of USD 4,000/month (OR=1.833, $\mathrm{p}=0.018)$. Children in grades $3-6$ were 1.8 times more likely to have anxiety-related disorders than those in grades $1-2(O R=1.79, p=0.024)$.

CONCLUSIONS: Anxiety-related disorders are common among Arabic-speaking Omani children and adolescents. They are more likely to be reported in middle scholastic grade levels and children from families with marital discord and low socioeconomic status. It is not clear whether the presently observed rates of anxiety exceed the prevalence that would have been observed pre-COVID-19 era. More studies are therefore warranted using children and adolescents' self-reported scales.

\section{Background}

A novel strain of coronavirus, entitled 'Severe Acute Respiratory Syndrome Coronavirus 2 (SARS-CoV-2), was first identified to affect human beings in December 2019, and subsequently reported to trigger respiratory illness. SARS-CoV-2 comes to be known as coronavirus disease 2019, or COVID-19 [1]. The World Health Organization (WHO) declared the outbreak a public health emergency of international concern in January 2020, and a pandemic on March 11, 2020 [ㄹ]. As of April 1, 2021, more than 2 million deaths worldwide were attributed to COVID-19 [ ${ }^{3}$ ].

While vaccines continued to be dispensed in different parts of the world, preventive measures are widely considered to be the most effective means to curb the rising tide of COVID-19, to date $\left.{ }^{4}\right]$. Social and physical distancing, including quarantines and travel restrictions, have curbed all forms of social interactions in public settings such as educational institutions, workplaces, playgrounds, theatres, and marketplaces $\left.{ }^{4}\right]$. These measures have been postulated to harm the social and emotional functioning of children and adolescents [5]. Overall, emerging data suggests that children and adolescents are adversely affected by the COVID-19 pandemic, and there is a rising tide of poor mental health outcomes in them $\left.{ }^{6}\right]$. This is congruent with other literature that observes that during periods of economic and social instability, there is a high risk of disruption of family functioning, parental stress, and caustic relationships in households [7]. As a result, situations arise that echoes the proverb "when 
elephants fight, it is the grass that suffers", which implies that during periods of family disruption, it is the weak or 'dependant' individuals that typically suffer. Meherali et al. $\left.{ }^{8}\right]$ conducted a systematic review and thematically analyzed the impact of the pandemic on children and adolescents' mental health. The authors concluded that this age group has high-risk factors for poor mental health outcomes that are likely to persist even after lockdown measures are relaxed. The conclusion is consistent with vast empirical data suggesting poor mental health among adults often has roots in childhood adversity [ $\left.{ }^{9}\right]^{-}$

Orgilés et al. [ ${ }^{10}$ ] surveyed 1,143 parents of Italian and Spanish children aged 3 to 18 years old for the emotional impact of the quarantine on children. This study indicated that approximately $86 \%$ of the parents noted changes in the functioning of their children during the quarantine, displaying cognitive symptoms as well as having a spectrum of internalizing and externalizing behavior problems. In the UK, Groarke et al. [11] examined the prevalence of loneliness during the pandemic. The study was conducted among the general population, and the data revealed that the observed prevalence rate of loneliness was more prevalent among the younger age group.

Even before the pandemic, there was evidence to suggest that forced isolation is associated with increased risk factors for poor mental health outcomes. Loades et al. [ ${ }^{12}$ ] conducted a systematic review of 63 studies on the impact of forced social isolation on the mental health of children and adolescents. This critical appraisal, which spans from the year 1946 to 2020, suggested that children and adolescents in enforced isolation are likely to manifest higher rates of affective symptoms. Supporting this conclusion, Magson et al. [13] reported that adolescents in Australia tend to experience pronounced elevated scores in indices of affective symptoms during the COVID-19 pandemic. Of note, this longitudinal study suggests that there is an increment of such distress as adolescents continued to dwell in confinement. In the Chinese population, Zhang et al. $\left[{ }^{14}\right]$ conducted longitudinal studies on the presence of affective symptoms and suicidal behavior among Chinese children and adolescents prior to the COVID-19 outbreak and after the lockdown was lifted. The authors reported poor mental health outcomes persisting after the lockdown. These studies all strongly imply that lockdowns tend to toil on the mental health integrity of younger age. Thus, careful attention to the identification and mitigation of poor mental health outcomes during formative years has the potential to reduce many adverse health and social outcomes that have the potential to persist in adulthood $\left[^{9}\right]$.

While there is robust evidence of the COVID-19 pandemic tending to increase loneliness and leading to poor mental health outcomes among children and adolescents in other parts of the world to date [ $\left.{ }^{12}\right]$, there is a dearth of studies from the Arabian Gulf countries. Arabian Gulf countries such as Oman. In demographic parlance, Oman is currently in the midst of the second stage of demographic transition, implying a high birth rate and predominance of the younger age group. It currently has a pyramidal population structure with a "youth bulge" [15].

The global pandemic of COVID-19 reached Oman on February 24, 2020, when two cases of COVID-19 were confirmed in the country $\left.{ }^{16}\right]$. During the time this study was conducted, there were 73,791 positive cases of COVID19 and approximately 359 deaths due to COVID-19 complications. The spike of cases led to the imposition of nationwide lockdowns. Educational institutions bore the brunt of the fallout of COVID-19. On May 7, 2020, the Ministry of Education decreed to close all educational centers. There was a period when there were intermittent allowances for secondary school students to attend classes, but the increasing number of cases eventually resulted in only 'tele-education' or e-learning being allowed. 
This study has been conducted to explore whether the prevailing enforced social isolation during the COVID-19 pandemic has adversely impacted the psychological functioning of children and adolescents in Oman, manifesting as anxiety-related disorders. Specific aims of this study were to examine the prevalence of anxiety-related disorders in this age group, as well as the contributing variables associated with them.

\section{Methodology}

\section{PARTICIPANTS}

This cohort study is part of wider study exploring mental health factors associated with early adversity among children in the GCC with particular reference to Oman, Saudi Arabia and Kuwait. The present study report on the cohort from Oman.

This is a web-based cross-sectional analytic study, carried out over 2 weeks between the $1^{\text {st }}$ and $15^{\text {th }}$ of August, 2020. The present study recruited consenting parents of children and adolescents (aged 8-18). Oman has two types of educational systems - private and public (or 'governmental'), and students from both were enrolled in the study. The Ministry of Education finances the latter education system, providing services free of charge up to the end of secondary education (grade 12). With the majority of Oman's being under 20 years of age, national educational initiatives have grown exponentially in recent years, from three formal schools with 900 students in the previous decades, to 1053 public schools currently. In urban areas, there has been concurrent growth of private schools, which provide a bilingual stream of education.

Inclusion criteria consisted of the parents of children between the ages of 8 to 18 residing in Oman during the pandemic. Exclusion criteria consisted of the parents of children in schools catering to children and adolescents with special needs. In Oman, children with severe cognitive and social deficits often attend specialized schools for the 'handicapped'. However, children who are higher functioning with milder forms of learning disabilities are generally accommodated for in mainstream education. The protocol of the present study was not equipped to exclude such children and adolescents. Children with a diagnosis or history of behavioral and/or mental disorders prior to the onset of the pandemic was another exclusion criterion that was considered.

\section{PROCEDURE}

After obtaining ethical approval from the Institutional Research Board (IRB) ( Centre of Studies and Research, Ministry of Health), the Ministry of Education overseeing public and private school education was approached to obtain official permission and cooperation to conduct the survey. The competent authorities for the schools residing in different parts of the country were contacted to cooperate in conducting this survey. At the time this study was conducted, there were 2,046 schools officially registered in the 11 muhafazah or administrative regions of Oman [ $\left.{ }^{17}\right]$, with a total number of 843,598 students (with an average of 27 students per class) [ ${ }^{18}$ ]. Attempts were made to recruit participants from all the 11 muhafazah. One school - private or public - was randomly sampled from each muhafazah.

To conduct the study, the concerned school authorities that responded to the investigators' initial inquiry were contacted through e-mail, WhatsApp, or via phone calls to elaborate on the purposes of the survey. Google forms were then sent through email and WhatsApp to the principals of the targeted schools.

\section{SAMPLE SIZE CALCULATION}

Page 5/20 
We based our sample size on a previous study about the prevalence of depression in attendees of urban primary healthcare centers in Oman, using the patient health questionnaire (PHQ), the study reported the prevalence of depressive symptoms to be $8.1 \%$ (Al-Salmani et al., 2015) $\left[{ }^{19}\right]$. With a 95\% confidence interval, a $2.5 \%$ margin of error, and with unknown population size, by using online software (EPITOOLS, 2020) $\left.{ }^{20}\right]$ the required sample size for the survey was calculated to be 458 .

\section{DATA COLLECTION}

Parents who fulfilled the inclusion and exclusion criteria were requested to complete the study survey. In the attached description of the study, participants were explicitly informed that they were at liberty to terminate their participation in the study at any time if they so wish, without providing any justifications to the investigators. Written informed consent was collected from all participants. The survey was anonymous, and the confidentiality of personal information collected was assured. Questionnaires were available both in English and in Arabic. Google forms were used to generate the questionnaires and links for parents were distributed using email and social media platforms. The returned surveys that were deemed to be invalid were excluded, and a total of 1500 valid responses were received. This gave a response rate of $52 \%$.

\section{OUTCOME MEASURE}

\section{The Screen for Child Anxiety Related Disorders}

Children and adolescents anxiety-related disorders, such as Generalized Anxiety, Separation Anxiety Disorder, Social Anxiety Disorder, School Phobia, as well as panic and somatic distress often accompanying such Anxiety Disorders, have been widely screened for using the Screen for Child Anxiety Related Disorders (SCARED-41) [ $\left.{ }^{21}\right]$. SCARED-41 constitutes of five-factor structure subtypes of anxiety-related disorders as defined by the DSM IV-TR

classification [21-23]. There are two versions - a child version, where children are meant to self-report their answers (SCARED-C), and a parent version, where parents are to answer the questionnaire as a proxy for their children (SCARED-P). Responses are recorded on a 3-point Likert scale ( 0 = "Not True, or Hardly Ever True", 1 = "Somewhat True or Sometimes True" or 3 = "Very True or Often True"). Some studies have suggested that child and parent versions of the SCARED-41 questionnaire have a high degree of concordance $\left.{ }^{21}\right]$, but there have also been studies that indicate that informant discrepancy may reduce the reliability of the parent version $\left.{ }^{24,25}\right]$.

The current study employed the use of the parental version (P-SCARED-41), which includes 41 items to screen for recent signs and symptoms of anxiety disorders in children (specifically, over three months prior to the participant filling the questionnaire) $\left[{ }^{21}\right]$. The rationale behind using the parental version is the ongoing pandemic posing difficulties for the investigators to contact both children and their parents, which would be necessary as parents or guardians are required to provide consent for their ward (between the ages of 0 to 18 years) to participate in online research. For this reason, only parents were approached to fill the research instrument.

P-SCARED-41 has been translated into various languages and their psychometric properties have been reported to be adequate $\left[{ }^{26}\right]$ including the presently used Arabic version $\left[{ }^{27,28}\right]$. English is also widely spoken in Oman, and to accommodate non-Arabic-speaking parents, the English version of P-SCARED-41 was also included. Both versions of the SCARED-41 questionnaire are publicly available $\left.{ }^{29}\right]$. 
The internal consistency of the P-SCARED-41 questionnaire used in the current study was found to be adequate (Cronbach's $\mathrm{a}=0.89$ ). A reported questionnaire yielding a total score of 25 or above is considered suggestive of a clinically significant anxiety disorder [ $\left.{ }^{30}\right]$. Hence, this cut-off point was used in this study to indicate the presence of anxiety. In addition to the SCARED-41 questionnaire, the Google form consisted of questions devoted to collecting detailed sociodemographic data of the children and their parents, as shown in Table 1. Questions focusing on certain challenges faced by them owing to the unique circumstances of the COVID-19 pandemic and the resultant lockdown were also asked, and the data collected is presented in Table 1.

\section{STATISTICAL ANALYSIS}

Data was analyzed by IBM Statistical Package for Social Sciences or SPSS (IBM SPSS23.0 NY, USA), and the results of those who were identified as having anxiety symptoms (SCARED score $>=25$ ) or identified as without anxiety symptoms (SCARED score< 25) were analyzed using descriptive statistics. Univariate analysis was conducted, and demographic variables were evaluated with the chi-square test and odds ratio (OR) to explore the association between the two groups. Next, multivariate analysis was conducted using a logistic regression model, with anxiety disorder status as the dependent variable, and those variables with $p<0.05$ in the univariate analysis as the independent variables, and concurrently adjusted by each other. This analysis helped address the research aim to identify the contributing variables associated with an anxiety disorder. A p-value of $<0.05$ was considered statistically significant.

\section{ETHICAL APPROVAL}

This study was approved by the Centre of Studies and Research at the Ministry of Health (MoH/CSR/19/10009). Informed and signed consent was obtained from the parents or guardians of the children. The study was conducted following the Declaration of Helsinki with regard to ethical human research, including confidentiality, privacy, and data management.

\section{Results}

A total of 790 participants fulfilled the inclusion criteria. Table 1 presents the results for both the parent's (or 'Respondent's') and children's demographic variables. Out of 790 children, 33.3\% ( $n=263)$ fulfilled the screening criteria for anxiety disorder as defined by the SCARED-41 scale. More mothers participated in the study ( $n=627$, $79.4 \%)$ than fathers (20.6\%). The majority of the respondents were married $(n=743,94.1 \%)$, more than $70 \%(n=623)$ were $\geq 35$ years old. More than half $(n=426,54.0 \%)$ of them had an income below USD 1, 999 per month, and $93.9 \%(n=742)$ of them were employed during the COVID-19 pandemic. More than $70.0 \%(n=627)$ of the respondent mothers had a high school level or lower education level $(n=437,55.3 \%)$. In contrast, a majority of the respondent fathers had a college degree or higher education level $(n=437,55.3 \%)$. The majority of the children of the participants were aged 8-11 years old $(n=730,92.4 \%)$ with more than $61 \%(n=483)$ studying in grades $3-6$. The proportion of girls $(49.0 \%)$ and boys $(51.0 \%)$ were almost equal.

\section{[TABLE 1 TO BE INSERTED HERE]}

Table 2 shows univariate and multivariate (logistic regression) analysis for sociodemographic data and its association with the child's anxiety. In the univariate analysis, a significant association was found between anxiety disorders and marital status of the parent ('not married' vs. 'married', p=0.043), educational level of themother ('college degree' vs. 'post-graduate', $p=0.037$ ), family income per month ('<1,000' vs. '4,000', $p=0.002 ; 1,000-1,999$ 
vs. 4,000, $p=0.021$ ), and the child's grade level at school ('7-12' vs. '1-2', $p=0.014$; '3-6' vs. '1-2', $p=0.009)$. The multivariate logistic analysis suggested a significant association of three demographic variables with the child's anxiety disorders. The model showed that children whose parents were divorced or separated were 1.9 times $(\mathrm{OR}=1.93, \mathrm{p}=0.035)$ more likely to have anxiety disorders than children who had parents who were married. Children whose family income was below USD 1,000 per month were 1.8 times $(O R=1.83, p=0.018)$ more likely to have anxiety disorders than those with a family income of USD 4,000 per month. Children in grades 3-6 were 1.8 times $(\mathrm{OR}=1.79, \mathrm{p}=0.024)$ more prone to have anxiety disorders than those in grades 1-2.

\section{[TABLE 2 TO BE INSERTED HERE]}

\section{Discussion}

Studies examining the prevalence of child and adolescent mental health problems have only recently begun to emerge from the Arabian Gulf countries such as Oman. The prevalence rates of children and adolescents in Oman with disordered eating habits is an estimated 9.5\% $\left[{ }^{31}\right]$, those with autism spectrum disorders in the range of 1.420.35/10,000 [ $\left.{ }^{32}\right]$, and those with ADHD an estimated 8.8\% [ $\left.{ }^{33}\right]$. Other children and adolescents' mental health problems, including but not limited to social phobia, mood disorders, learning disorders, and other adverse childhood experiences have also been reported [ ${ }^{34}$ ]. In Uganda, it has been widely speculated that among many varied child mental health problems, anxiety appears to be most prevalent with a figure ranging from $10-20 \%$ of children and adolescents exhibiting core symptoms of anxiety-related disorders $\left.{ }^{35}\right]$. In the USA, using a face-toface survey of 10123 Americans (ages between 13 and 18 years), Burstein et al. $\left[{ }^{36,37}\right]$ reported that around $3 \%$ and $9 \%$ of the participants have core features of generalized anxiety disorder. In a recent meta-analysis of six Arabian Gulf countries by Chan et al. [ $\left.{ }^{38}\right]$, out of the accrued 33 studies that fulfilled study criteria, the pooled prevalence of anxiety symptoms ranged from $17.27 \%$ to $57.04 \%$. This critical appraisal covered the pre-pandemic era. It is not clear how the pandemic and all of the resulting tribulations have affected the child and adolescent population in Oman.

The COVID-19 pandemic has resulted in children and adolescents experiencing unprecedented interruptions to their daily lives, which are likely to precipitate poor mental health outcomes [ ${ }^{8}$ ]. Studies carried out in different parts of the world during the pandemic strongly suggest this outcome, with the assumption that enforced social isolation is adversely impacting children's psychological functioning which is, in turn, conventionally manifesting as anxietyrelated disorders $[6,7,8,10,11]$. Therefore, the present study has been conducted to investigate the prevalence rate of anxiety-related disorders in the children and adolescents of Oman during the COVID-19 pandemic.

Prior to the COVID-19 pandemic, the international prevalence of child and adolescent mental health problems constituted $13.4 \%$ of the sample of the 27 countries surveyed, with those afflicted with anxiety-related disorders constituting $6.5 \%$ of the pooled sample [ $\left.{ }^{39}\right]$. In the United States, Hawes et al. $\left[{ }^{40}\right]$ suggested that the frequency of anxiety-related disorders tend to strongly hinge on whether the region is experiencing a period of peak infection rates and having resultant lockdowns. This implies that anxiety-related disorders are situational. Compared to the global rate before the COVID-19 pandemic, the present rate appears to be higher than the pooled prevalence of $13.4 \%$. There are various instruments available to solicit the presence of anxiety disorders, and the reported prevalence rates of these disorders may be impacted by the instrument used to study them. Studies that specifically employ the SCARED questionnaire also may have results that are likely to vary when using the selfrated child version or when answering by proxy using the parent version. Therefore, comparisons between various 
studies would likely echo the metaphor of 'comparing apples and oranges', if this factor is not taken into consideration.

The present study in Oman suggests that 33.3\% ( $n=263)$ fulfilled the criteria for anxiety disorders, as defined by the SCARED questionnaire. In comparison, Ravens-Sieberer et al. $\left[{ }^{41}\right]$ conducted a nationally representative study (7- to 17-year-old children and adolescents) in Germany employing the child self-rated SCARED questionnaire, reporting a $24.1 \%$ prevalence of children who have reached the threshold for case-ness of anxiety-related disorders. In Iran, among adolescents with hearing loss during the COVID-19 pandemic, Ariapooran and Khezeli [ ${ }^{42}$ ] reported $37.5 \%$ of the study participants having anxiety-related symptoms.

In several non-western societies, socio-cultural patterning tends to predominantly usher children into the collective mindset. There is evidence to suggest a tendency to lean towards a 'collective' social orientation, which is in contrast to 'individualistic' social orientation commonly found in Western countries. To preserve social harmony, according to Al Asmi et al. [43], "such a society tends to discourage the expression of emotion and therefore relegates emotional distress. Instead, distress is expressed in somatic terms, a feat that is orthogonal to what may constitute emotional distress in the psychiatric nomenclature..." (p.6). To extrapolate from such a view in the context of anxiety symptoms, being marked with somatic distress, anxiety symptoms are likely to be recognized and acknowledged by the parents of the children in Oman. In contrast, this view would imply that emotional distress, since it is stigmatized, is unlikely to be acknowledged. With this background, it is, therefore, safe to speculate that anxiety symptoms were highly endorsed by the parents because their manifestation does not contravene socio-cultural teachings. In the regions in the global south with the bulk of its population being children and adolescents, studies are needed to explore the interplay between cultural patterning and odium to distress.

As is often the case, mental distresses tend to be intimately linked to socio-demographic factors. To address such a link, the related aims of this study is to comprehensively examine which demographic factors unique to this period contribute to the development of anxiety symptoms solicited by Screen for Child Anxiety Related Disorders (SCARED-41).As shown in Table 1, this study accrued various sociodemographic factors including the type of family caregivers (mother or father). The majority of respondents to the survey were mothers rather than fathers, constituting $79.4 \%$ of the sample. Other sociodemographic sought from the parent included marital status of the parent, educational level of both parents, family income, current working status, family history of mental illness. For the children and adolescents, the grade age and gender of the child were sought. Both univariate and multivariate analysis was used to examine the associated factors with symptoms of anxiety. As shown in Table 2 , socio-demographic factors significantly associated with anxiety symptoms include having divorced or separated parents, a family income below 1000 US dollars, and studying in scholastic grade levels between 3 to 6 . These significant associated factors are recapitulated within the background literature below in tandem.

First, divorce was significant in the regression analysis. Recent divorce or separation may be likely to cause an acute stress reaction that may contribute to the chronicity of poor mental health outcomes. This study could not determine whether the divorce coincided with the outbreak of the pandemic or whether it preceded the pandemic. Current data shows that most of the respondents were married and were 35 years or older. Divorced or separated parents consisted of $8.4 \%$ of participants whose children were significantly associated with higher SCARED scores. It is well known that regardless of age, gender, and culture, children of divorced parents experience tend to succumb to poor coping mechanisms, and this could culminate in an increased risk of developing poor mental health outcomes [ $\left.{ }^{44}\right]$. Future studies, if the present study withstands further scrutiny, should define the types of separation or divorce and whether they occurred during the pandemic. It should also be critical to unravel whether 
the divorce/separation is recent or not. In addition to divorce or separation, it has been widely documented that required quarantine and social isolation have significantly reduced the opportunity to escape from caustic home environments. As a result, according to Lebow [ $\left.{ }^{45}\right]$, "couples fall into angry exchanges without resolution or into patterns of demand-withdrawal, which may degenerate into protracted high conflict and sometimes domestic violence. In parallel, social interactions and social support that might mitigate tensions are decreased" (p. 968). This echoes the proverb "When the elephants fight, the grass gets trampled" $\left.{ }^{46}\right]$. Studies are needed on whether periods of quarantine and isolation, unstable family dynamics, and separation from a parental figure can be detrimental for children requiring greater amounts of emotional support.

Second, according to regression analysis family income was significant. Some studies suggest that the pandemic disproportionately affects children who are at a socio-economic disadvantage $\left[{ }^{47,8}\right]$. In support of such a view, the present study showed that there is an association with the higher SCARED score in children and adolescents of families with low socio-economic status (specifically, those with a family income below 1,999 USD per month). Low-income families are facing greater degrees of financial instability during the pandemic, with enforced lockdowns and curfews making it challenging for parents to meet the demands of dependent family members and children. The pandemic has also caused economic instability in the country which, in turn, is causing a lack of job security and fluctuating incomes $\left[{ }^{48}\right]$. The resultant increased psychological burden on parents can simultaneously affect their children as well, which is a phenomenon that has been widely documented in the setting of the COVID19 pandemic, including countries like Italy, Germany, and China [ $\left.{ }^{49-51}\right]$.

Third, in addition to marital status and income, the scholastic grade of the children and adolescents was also significant. The majority were in the 8-11-year-old age group. The distribution of gender of the children was nearly equal (girls $=49.0 \%$, boys $=51.0 \%$ ). The participants with children attending grades 3 to 6 (usually including children in the 8-11-year-old age group) reported higher SCARED scores than other groups. One possibility for this is that at this age, children would likely be going to school under normal circumstances and therefore, the lockdown has limited their interactions with their peers. There is vast psychological literature suggesting that children of this age tend to develop social behaviors by interacting with their peers, rather than with their parents ${ }^{52}$ ]. It is plausible that separation from their peers, as well as lack of access to social settings like playgrounds, have rendered these children vulnerable to increased anxiety and loneliness. Therefore, youth at this grade level may experience a greater interruption to their daily social life, causing more psychological distress [ $\left.{ }^{53,12}\right]$.

Thus, the aforementioned factors associated with higher SCARED scores in children and adolescents include living in divorced households or with low family income. The age group is another factor that contributed to the development of higher SCARED scores. The present identification of socio-demographic factors contributing to the development of anxiety symptoms has the potential to lay the groundwork for contemplating prevention of poor mental health outcomes during and after the period of the COVID-19 pandemic.

\section{LIMITATIONS:}

These types of studies are prone to many limitations, and the most notable ones will be highlighted here. First, the generalization of this study is hampered by the fact that it was an online survey rather than a traditional pen and paper format. It is not clear whether the response rate tends to be higher among those who are 'technologically savvy', and might exclude parents who are not as technologically proficient. Oman has a high penetration of internet access, which has increased significantly in tandem with the onset of the pandemic and a resultant shift to

online learning and working from home $\left[{ }^{54}\right]$. Second, this study aims for the nationally representative parent of the 
school-going population. The bulk of Oman's population is under the age of 20 years, and the present sample might fall short of the required national representative. This is a significant limitation of this study until large community surveys are conducted. Third, the study is likely to be limited by the fact that the parent version of the SCARED scale was used. It is not clear whether such a proxy approach adequately reflects the spectrum of anxiety-related symptoms among children and adolescents. Further study of the reliability of this version of the questionnaire is therefore warranted. In another study utilizing the Arabic version of the SCARED questionnaire, it was found to have a parallel capacity to the original English version of identifying the presence of anxiety-related disorders $\left.{ }^{55}\right]$. In this study, both Arabic and English P-SCARED-41 were used. Future studies could examine whether different language versions of the P-SCARED-41 report similar results. Fourth, the cross-sectional design of this study provides a limited view of the longitudinal course of the mental well-being of the studies' participants. It is not clear whether the observed anxiety symptoms constitute acute stress reaction adjustment disorder or fullfledged anxiety symptoms with all the negative repercussions this is likely to have. Last but not least, while SCARED has been molded to follow the criteria of DSM, soliciting emotional symptoms via an online questionnaire is considered suboptimal compared to gold standard structured interviews particularly tailored to non-western populations, where there is likely to be culture-specific idioms for distress and anxiety disorders [ ${ }^{31}$.

\section{Conclusion}

This study explores the frequency of anxiety-related disorders in children and adolescents during the COVID-19 pandemic. Using the Screen for Child Anxiety Related Disorders questionnaire with a cut-off of $>25$, one-third of the parents endorsed their children or adolescents to be marked with anxiety-related symptoms. The second aim is to explore the factors associated with anxiety-related disorders in children. The notable risk factors were having a family income corresponding to low socio-economic status, having divorced or separated parents, and being in middle-grade levels in school. If this study were to withstand scrutiny, children and adolescents could be directed towards available mental health services. The identification of risk factors and formulation of psychological interventions for vulnerable groups can significantly help mitigate the negative mental health impacts of the pandemic on the youth of the country.

\section{Abbreviations}

- OR: Odds ratio

- SCARED: Screen for Child Anxiety Related Disorders

- USD: US dollar

- WHO: World Health Organization

\section{Declarations}

\section{Ethics approval and consent to participate}

This study was approved by the Institutional Review Board (MoH/CSR/19/10009) under the auspice of the Ministry of Health. All participants were provided written informed consent to participate. An overseeing mental health professional declared all participants to be capable of providing ethical consent for their participation. Informed and signed consent was obtained from the parents or guardians of the children. The study was carried out under the Code of Ethics of the World Medical Association (Declaration of Helsinki) for human 
experiments.

\section{Consent for publication}

NA

\section{Availability of data and material}

Sharing this data has yet to be developed in Oman. Access to data can be obtained by application to the Postgraduate Studies \& Research (http://www.squ.edu.om/dor), College of Medicine and Health Sciences, Sultan Qaboos University. medpgsr@squ.edu.om.

\section{Competing interests}

None. The authors declare that there are no conflicts of/or competing interests.

\section{Funding}

This research received no specific grant from any funding agency in the public, commercial, or not-for-profit sectors.

\section{Authors' contributions}

Drs Muna Alshekaili, Walid Hassan, Ghaniya Saif Al Ghafri and Fatima Alsulimani had full access to all of the data in the study and take responsibility for the integrity of the data and the accuracy of the data analysis.

Acquisition, analysis, or interpretation of data: Yahya Al-Kalbani, Hassan Mirza, Moon Fai Chan, Waleed Hassan, Hanan Saif Al-Sumri, Ahmed Bait Amer, and Samir Al-Adawi ${ }^{3}$

Drafting of the manuscript: Aishwarya Ganesh, Salim Al Huseini, Moon Fai Chan, and Samir Al-Adawi

Critical revision of the manuscript for important intellectual content: Aishwarya Ganesh, Salim Al Huseini, Samir AlAdawi, Muna Al-Saadoonand Moon Fai Chan.

Statistical analysis: Moon Fai Chan, Salim Al Huseini, and Walid Hassan

Administrative, technical, or material support: Muna Alshekaili, Walid Hassan, Ghaniya Saif Al Ghafri, Fatima AlSulimani

Supervision: Muna Alshekaili, Walid Hassan, Ghaniya Saif Al Ghafri, and Fatima Al-Sulimani

\section{Acknowledgments}

The authors would like to express their sincere appreciation to the Ministry of Education and the selected schools for proving unstinting support to conduct this study.

\section{References}


1. Acter T, Uddin N, Das J, et al. Evolution of severe acute respiratory syndrome coronavirus 2 (SARS-CoV-2) as coronavirus disease 2019 (COVID-19) pandemic: A global health emergency. Sci Total Environ. 2020;730:138996.

2. World Health Organization (2020), WHO Director-General's statement on IHR Emergency Committee on Novel Coronavirus (2019-nCoV). https://www.hoint/dg/speeches/detail/who-director-general-s-statement-on-ihremergency-committee-on-novel-coronavirus-(2019-ncov). Accessed 13 October, 2021.

3. Kang S, Peng W, Zhu Y, et al. Recent progress in understanding 2019 novel coronavirus (SARS-CoV-2) associated with human respiratory disease: detection, mechanisms and treatment. Int J Antimicrob Agents. 2020;55(5):105950.

4. Chu DK, Duda S, Solo K, et al. Physical Distancing, Face Masks, and Eye Protection to Prevent Person-toPerson Transmission of SARS-CoV-2 and COVID-19: A Systematic Review and Meta-Analysis. J Vasc Surg. 2020;72(4):1500.

5. Golberstein E, Gonzales G, Meara E. How do economic downturns affect the mental health of children? Evidence from the National Health Interview Survey. Health Econ. 2019;28(8):955-970.

6. 6. Centers for Disease Control and Prevention. Data and statistics on children's mental health. https://www.cdc.gov/childrensmentalhealth/data.html. Accessed 27 March, 2020.

7. Feinberg ME, A Mogle J, Lee JK, et al. Impact of the COVID-19 Pandemic on Parent, Child, and Family Functioning. Fam Process. 2021 Apr 8. Epub ahead of print.

8. Meherali S, Punjani N, Louie-Poon S, et al. (2021). Mental Health of Children and Adolescents Amidst COVID19 and Past Pandemics: A Rapid Systematic Review. Int J Environ Res Public Health. 18(7), 3432.

9. Costello EJ, Maughan B. Annual research review: Optimal outcomes of child and adolescent mental illness. $J$ Child Psychol Psychiatry. 2015 Mar;56(3):324-41.

10. Orgilés M, Morales A, Delvecchio E, et al. Immediate Psychological Effects of the COVID-19 Quarantine in Youth From Italy and Spain. Front Psychol. 2020 Nov 6;11:579038.

11. Groarke JM, Berry E, Graham-Wisener L, et al. Loneliness in the UK during the COVID-19 pandemic: Crosssectional results from the COVID-19 Psychological Wellbeing Study. PLoS One. 2020;15(9):e0239698.

12. Loades ME, Chatburn E, Higson-Sweeney N, et al. Rapid Systematic Review: The Impact of Social Isolation and Loneliness on the Mental Health of Children and Adolescents in the Context of COVID-19. J Am Acad Child Adolesc Psychiatry. 2020 Nov;59(11):1218-1239.e3.

13. Magson NR, Freeman JYA, Rapee RM, et al. Risk and Protective Factors for Prospective Changes in Adolescent Mental Health during the COVID-19 Pandemic. J Youth Adolesc. 2021 Jan;50(1):44-57.

14. Zhang L, Zhang D, Fang J, et al. Assessment of Mental Health of Chinese Primary School Students Before and After School Closing and Opening During the COVID-19 Pandemic. JAMA Netw Open. 2020;3(9):e2021482.

15. Islam, M.M. Demographic transition in Sultanate of Oman: emerging demographic dividend and challenges. Middle East Fertil Soc J25, 7 (2020.

16. Khamis F, Al Rashidi B, Al-Zakwani I, et al. Epidemiology of COVID-19 Infection in Oman: Analysis of the First 1304 Cases. Oman Med J. 2020;35(3):e145.

17. Alshekaili M, Hassan W, Al Said N, et al. Factors associated with mental health outcomes across healthcare settings in Oman during COVID-19: frontline versus non-frontline healthcare workers. BMJ Open. 2020 Oct 10;10(10):e042030. 
18. Education; National Centre for Statistics \& Information. https://data.gov.om/OMEDCT2016/education? regions=1000000-oman\&indicators=1000080-number-of-schools. Accessed 13 April, 2021.

19. Al-Salmani A, Juma T, Al-Noobi A, et al. Characterization of depression among patients at urban primary healthcare centers in Oman. Int J Psychiatry Med. 2015;49(1):1-18.

20. EPITOOLS (2021), Ausvet, https://epitools.ausvet.com.au/. Accessed 20 September, 2021.

21. Birmaher B, Khetarpal S, Brent D, et al. The Screen for Child Anxiety Related Emotional Disorders (SCARED): scale construction and psychometric characteristics. J Am Acad Child Adolesc Psychiatry. 1997;36(4):545553.

22. Monga S, Birmaher B, Chiappetta L, et al. Screen for Child Anxiety-Related Emotional Disorders (SCARED): convergent and divergent validity. Depress Anxiety. 2000; 12(2):85-91.

23. American Psychiatric Association (2000). Diagnostic and statistical manual of mental disorders: DSM-IV (4 ${ }^{\text {th }}$ ed., Texas Revision). Washington (DC): American Psychiatric Association.

24. Cosi S, Canals J, Hernández-Martinez C, et al. Parent-child agreement in SCARED and its relationship to anxiety symptoms. J Anxiety Disord. 2010;24(1), 129-133.

25. Bowers ME, Reider LB, Morales S, et al. Differences in Parent and Child Report on the Screen for Child AnxietyRelated Emotional Disorders (SCARED): Implications for Investigations of Social Anxiety in Adolescents. J Abnorm Child Psychol. 2020;48(4):561-571.

26. Arab A, El Keshky M, Hadwin JA. Psychometric Properties of the Screen for Child Anxiety Related Emotional Disorders (SCARED) in a Non-Clinical Sample of Children and Adolescents in Saudi Arabia. Child Psychiatry Hum Dev. 2016 Aug;47(4):554-562.

27. Hariz N, Bawab S, Atwi M, et al. Reliability and validity of the Arabic Screen for Child Anxiety Related Emotional Disorders (SCARED) in a clinical sample. Psychiatry Res. 2013 Sep 30;209(2):222-228.

28. Alfakeh SA, Gadah AA, Alharbi KA, et al. Childhood anxiety disorders prevalence in Saudi Arabia. Saudi Med J. 2021 Jan;42(1):91-94.

29. Instruments: Screen for Child Anxiety Related Emotional Disorders (SCARED). https://www.pediatricbipolar.pitt.edu/resources/instruments. Accessed on 13 October, 2021

30. Hale WW 3rd, Crocetti E, Raaijmakers QA, et al. A meta-analysis of the cross-cultural psychometric properties of the Screen for Child Anxiety Related Emotional Disorders (SCARED). J Child Psychol Psychiatry. 2011 Jan;52(1):80-90.

31. Al-Adawi S, Dorvlo AS, Burke DT, et al. A survey of anorexia nervosa using the Arabic version of the EAT-26 and "gold standard" interviews among Omani adolescents. Eat Weight Disord. 2002 Dec;7(4):304-311.

32. Al-Mamri W, Idris AB, Dakak S, et al. Revisiting the Prevalence of Autism Spectrum Disorder among Omani Children: A multicentre study. Sultan Qaboos Univ Med J. 2019;19(4):e305-e309.

33. Al-Ghannami SS, Al-Adawi S, Ghebremeskel K, et al. Attention Deficit Hyperactivity Disorder and Parental Factors in School Children Aged Nine to Ten Years in Muscat, Oman. Oman Med J. 2018 May;33(3):193-199.

34. Al-Sharbati MM, Al-Farsi YM, Al-Sharbati ZM, et al. Profile of Mental and Behavioral Disorders Among Preschoolers in a Tertiary Care Hospital in Oman: A Retrospective Study. Oman Med J. 2016;31(5):357-364.

35. Abbo C, Kinyanda E, Kizza RB, et al. Prevalence, comorbidity and predictors of anxiety disorders in children and adolescents in rural north-eastern Uganda. Child Adolesc Psychiatry Ment Health. 2013; 7: 21. 
36. Burstein M, Beesdo-Baum K, He JP, et al. Threshold and subthreshold generalized anxiety disorder among US adolescents: Prevalence, sociodemographic, and clinical characteristics. Psychol Med. 2014; 44: 2351-2362.

37. Burstein M, He JP, Kattan G, et al. Social phobia and subtypes in the national comorbidity survey-adolescent supplement: prevalence, correlates, and comorbidity. J Am Acad Child Adolesc Psychiatry. 2011; 50: 870-880.

38. Chan MF, Al Balushi R, Al Falahi M, et al. Child and adolescent mental health disorders in the GCC: A systematic review and meta-analysis. International Journal of Pediatrics \& Adolescent Medicine. 2021 Sep;8(3):134-145.

39. Polanczyk GV, Salum GA, Sugaya LS, et al. Annual research review: A meta-analysis of the worldwide prevalence of mental disorders in children and adolescents. J Child Psychol Psychiatry. 2015 Mar;56(3):34565.

40. Hawes MT, Szenczy AK, Olino TM, et al. Trajectories of depression, anxiety and pandemic experiences; A longitudinal study of youth in New York during the Spring-Summer of 2020. Psychiatry Res. 2021 Apr;298:113778.

41. Ravens-Sieberer U, Kaman A, Erhart M, et al. Impact of the COVID-19 pandemic on quality of life and mental health in children and adolescents in Germany. Eur Child Adolesc Psychiatry. 2021 Jan 25:1-11. Epub ahead of print.

42. Ariapooran S, Khezeli M. Symptoms of anxiety disorders in Iranian adolescents with hearing loss during the COVID-19 pandemic. BMC Psychiatry. 2021 Feb 22;21(1):114.

43. Al-Asmi A, Al-Rawahi S, Al-Moqbali ZS, et al. Magnitude and concurrence of anxiety and depression among attendees with multiple sclerosis at a tertiary care Hospital in Oman. BMC Neurol. 2015;15:131.

44. D’Onofrio B, Emery R. Parental divorce or separation and children's mental health. World Psychiatry. 2019;18(1):100-101.

45. Lebow JL. The challenges of COVIDCOVIDseparation andnd post-divorce families. Fam process. 2020 Sep;59(3):967-973.

46. Simpson J, Speake, J (2008). The Oxford Dictionary of Proverbs (5 ed.). https://www.oxfordreference.com/view/10.1093/acref/9780199539536.001.0001/acref-9780199539536-e650. Accessed 13 October, 2021

47. Li W, Wang Z, Wang G, et al. Socioeconomic inequality in child mental health during the COVID-19 pandemic: First evidence from China. J Affect Disord. 2021 May 15;287:8-14.

48. Owtram F, Hayek M (2020). Oman in the COVID-19 Pandemic: People, Policy and Economic Impact. https://blogs.Ise.ac.uk/mec/2020/07/23/oman-in-the-covid-19-pandemic-people-policy-and-economicimpact/. Accessed 12 August, 2020

49. Spinelli M, Lionetti F, Pastore $M$, et al. Parents' stress and children's psychological problems in families facing the COVID-19 outbreak in Italy. Front Psychol. 2020 Jul 3;11:1713.

50. Huebener M, Waights S, Spiess CK, et al. Parental well-being in times of Covid-19 in Germany. Rev Econ Househ. 2021;1-32.

51. Liu Q, Zhou Y, Xie X, et al. The prevalence of behavioral problems among school-aged children in home quarantine during the COVID-19 pandemic in china. Journal of affective disorders. 2021 Jan 15;279:412-416.

52. Alhuzimi T. Stress and emotional wellbeing of parents due to change in routine for children with Autism Spectrum Disorder (ASD) at home during COVID-19 pandemic in Saudi Arabia. Res Dev Disabil. 2021 Jan 1;108:103822.

Page 15/20 
53. Laursen B, Bukowski WM, Aunola K, et al. Friendship moderates prospective associations between social isolation and adjustment problems in young children. Child development. 2007 Jul;78(4):1395-1404.

54. Kemp S. OMAN: DIGITAL 2020. https://datareportal.com/reports/digital-2020oman\#: :text=Internet\%20penetration\%20in\%200man\%20stood\%20at\%2092\%25\%20in\%20January\%202020. Accessed 14 April, 2021

55. Hariz N, Bawab S, Atwi M, et al. Reliability and validity of the Arabic Screen for Child Anxiety Related Emotional Disorders (SCARED) in a clinical sample. Psychiatry Res. 2013 Sep 30;209(2):222-228.

\section{Tables}


Table 1. Characteristics of the parents of children and adolescents (aged 8- 18) $(n=790)$

Demographic n (\%)

\section{Respondent}

Father of the child

$163(20.6)$

Mother of the child (ref)

$627(79.4)$

Marital status of the parent

Divorced/Separated

$47(5.9)$

Married (ref)

$743(94.1)$

Age (Years) of the respondent

$<=34$

167 (21.1)

35-44

456 (57.7)

$45+$ (ref)

$167(21.2)$

Educational level - Father

High school or below

$353(44.7)$

College degree

250 (31.6)

Post-graduated (ref)

$187(23.7)$

Educational level - Mother

High school or below

437 (55.3)

College degree

185 (23.4)

Post-graduated (ref)

$168(21.3)$

Family income/month (USD)

$<1,000$

134 (17.0)

1,000-1,999

$292(37.0)$

2,000-3,999

177 (22.4)

$4,000+$ (ref)

$187(23.6)$

Current working status

Not work (unpaid leave/terminated)

$48(6.1)$

Working (ref)

$742(93.9)$

Paid leave

$160(21.6)$

Working fewer hours

$129(17.4)$

Working regular hours

$415(55.9)$

Working more hours

$38(5.1)$ 
Family history of mental illness

\begin{tabular}{lc} 
Yes & $27(3.4)$ \\
\hline No & $763(92.6)$ \\
\hline Grade level of the child & $115(14.6)$ \\
\hline $7-12$ & $483(61.1)$ \\
\hline $3-6$ & $192(24.3)$ \\
\hline $1-2$ (ref) & $730(92.4)$ \\
\hline Age (Years) of the child & $60(7.6)$ \\
\hline $8-11$ & \\
\hline $12-18$ (ref) & $387(49.0)$ \\
\hline Gender of the child & $403(51.0)$
\end{tabular}


Table 2. Univariate and multivariate (logistic regression) analysis for anxiety disorder in association of demographic factors

\begin{tabular}{|c|c|c|c|c|c|c|}
\hline & \multicolumn{2}{|c|}{ Anxiety Disorder } & \multirow{2}{*}{\multicolumn{2}{|c|}{$\begin{array}{l}\text { Univariate } \\
\text { analysis }\end{array}$}} & \multirow{2}{*}{\multicolumn{2}{|c|}{ Multivariate analysis^ }} \\
\hline & $\begin{array}{l}\text { Yes } \\
(n=263)\end{array}$ & $\begin{array}{l}\text { No } \\
(n=527)\end{array}$ & & & & \\
\hline Demographic & $\mathrm{n}(\%)$ & $\mathrm{n}(\%)$ & OR & $p$-value & OR & $p$-value \\
\hline \multicolumn{7}{|l|}{ Respondent } \\
\hline Father of the child & $56(21.3)$ & $107(20.3)$ & 1.062 & 0.746 & & \\
\hline Mother of the child (ref) & $207(78.7)$ & $420(79.7)$ & & & & \\
\hline \multicolumn{7}{|c|}{ Marital status of the parent } \\
\hline Divorced/Separated & $22(8.4)$ & $25(4.7)$ & 1.833 & $0.043^{\star}$ & 1.931 & $0.035^{\star}$ \\
\hline Married (ref) & $241(91.6)$ & $502(95.3)$ & & & & \\
\hline \multicolumn{7}{|c|}{ Age (Years) of the respondent } \\
\hline$<=34$ & $69(26.2)$ & $98(18.6)$ & 1.557 & 0.053 & & \\
\hline $35-44$ & $142(54.0)$ & $314(59.6)$ & 0.999 & 0.999 & & \\
\hline $45+$ (ref) & $52(19.8)$ & $115(21.8)$ & & & & \\
\hline \multicolumn{7}{|l|}{ Educational level - Father } \\
\hline High school or below & $118(44.8)$ & $235(44.6)$ & 1.117 & 0.569 & & \\
\hline College degree & $87(33.1)$ & $163(30.9)$ & 1.187 & 0.406 & & \\
\hline Post-graduated (ref) & $58(22.1)$ & $129(24.5)$ & & & & \\
\hline \multicolumn{7}{|l|}{ Educational level - Mother } \\
\hline High school or below & $141(53.6)$ & $296(56.2)$ & 1.263 & 0.244 & 1.15 & 0.506 \\
\hline College degree & $76(28.9)$ & $109(20.7)$ & 1.849 & $0.037 *$ & 0.728 & 0.101 \\
\hline Post-graduated (ref) & $46(17.5)$ & $122(23.1)$ & & & & \\
\hline \multicolumn{7}{|c|}{ Family income/month (USD) } \\
\hline$<1,000$ & $57(21.7)$ & $77(14.6)$ & 2.085 & $0.002 *$ & 1.833 & $0.018 *$ \\
\hline $1,000-1,999$ & $106(40.3)$ & $186(35.3)$ & 1.605 & $0.021 *$ & 1.504 & 0.115 \\
\hline $2,000-3,999$ & $51(19.4)$ & $126(23.9)$ & 1.14 & 0.577 & 1.132 & 0.582 \\
\hline $4,000+($ ref) & $49(18.6)$ & $138(26.2)$ & & & & \\
\hline \multicolumn{7}{|l|}{ Current working status } \\
\hline $\begin{array}{l}\text { Not work (unpaid } \\
\text { leave/terminated) }\end{array}$ & $18(6.8)$ & $30(5.7)$ & 1.217 & 0.523 & & \\
\hline Working (ref) & $245(93.2)$ & $497(94.3)$ & & & & \\
\hline
\end{tabular}




\begin{tabular}{|c|c|c|c|c|c|c|}
\hline Paid leave & $59(24.1)$ & $101(20.3)$ & 5.892 & 0.117 & & \\
\hline Working less hours & $38(15.5)$ & $91(18.3)$ & & & & \\
\hline Working regular hours & $130(53.1)$ & $285(57.4)$ & & & & \\
\hline Working more hours & $18(7.3)$ & $20(4.0)$ & & & & \\
\hline \multicolumn{7}{|c|}{ Family history of mental illness } \\
\hline Yes & $13(4.9)$ & $14(2.7)$ & 1.905 & 0.096 & & \\
\hline No & $250(95.1)$ & $513(97.3)$ & & & & \\
\hline \multicolumn{7}{|l|}{ Grade level of the child } \\
\hline $7-12$ & $44(16.7)$ & 71 (13.5) & 1.859 & $0.014^{\star}$ & 1.097 & 0.073 \\
\hline $3-6$ & $171(65.0)$ & $312(59.2)$ & 1.644 & $0.009 *$ & 1.793 & $0.024 *$ \\
\hline $1-2$ (ref) & $48(18.3)$ & $144(27.3)$ & & & & \\
\hline \multicolumn{7}{|l|}{ Age (Years) of the child } \\
\hline 8-11 & $247(93.9)$ & $483(91.7)$ & 1.406 & 0.257 & & \\
\hline $12-18$ (ref) & $16(6.1)$ & $44(8.3)$ & & & & \\
\hline \multicolumn{7}{|l|}{ Gender of the child } \\
\hline Girl & $128(48.7)$ & $259(49.1)$ & 0.981 & 0.899 & & \\
\hline Boy (ref) & $135(51.3)$ & $268(50.9)$ & & & & \\
\hline
\end{tabular}

Ref, reference point; Chi-square test; OR, Odds Ratio; *, sig., p<0.05; SCARED (Screen for Child Anxiety Related Disorders): Yes: 25+, No: $<25$;

^, Logistic (Enter); Hosmer and Lemeshow Test $\square^{2}=6.875, p=0.442$; Sensitivity $=61.6 \%$, Specificity $=54.3 \%$, overall predicting power $=56.7 \%$ 